\title{
STABILITAS DINDING PENAHAN TANAH DENGAN GROUND ANCHOR DAN METODE PELAKSANAANNYA PADA KONDISI IN-SITU DAN JENUH
}

\author{
Albert Aldo $^{1}$ dan Alfred Jonathan Susilo ${ }^{2}$ \\ ${ }^{1}$ Program Studi Sarjana Teknik Sipil, Universitas Tarumanagara, Jl. Letjen S. Parman No.1 Jakarta \\ Email:12albertaldo@gmail.com \\ ${ }^{2}$ Program Studi Sarjana Teknik Sipil, Universitas Tarumanagara, Jl. Letjen S. Parman No.1 Jakarta \\ Email: alfredsusilo@gmail.com
}

\begin{abstract}
ABSTRAK
Pencegahan kelongsoran pada tanah merupakan hal yang penting dalam dunia konstruksi, salah satu contoh pencegahannya adalah dengan menggunakan dinding penahan tanah. Dinding penahan tanah berfungsi untuk menahan beban lateral serta menyokong tekanan tanah dan air. Faktor terpenting dalam merencanakan dan membangun dinding penahan tanah adalah mengusahakan agar dinding penahan tanah tidak mengalami perpindahan yang melebihi batas ijin akibat gaya lateral, sehingga dinding penahan tanah harus diberikan perkuatan oleh ground anchor untuk menahan beban lateral dari timbunan tanah di belakang dinding penahan tanah. Kondisi tanah pada saat jenuh maupun tidak jenuh mempengaruhi keruntuhan yang dapat terjadi. Selain itu metode pelaksanaan konstruksi saat pemasangan ground anchor juga mempengaruhi yang dapat terjadi. Pada analisis ini metode yang digunakan yaitu metode analisis stabilitas pada dinding penahan tanah dengan pengecekan terhadap guling, geser, dan daya dukung tanah. Setelah itu dilakukan interpretasi hasil analisis pada kedua kondisi tanah dan berbagai metode pelaksanaan konstruksi pemasangan ground anchor untuk mengetahui faktor keamanan dari defleksi yang terjadi. Analisis ini mengkaji pada kondisi tanah apa serta pengaruh metode pelaksanaan konstruksi dari ground anchor yang akan mengalami keruntuhan paling besar.
\end{abstract}

Kata kunci: ground anchor, in-situ, jenuh, dinding penahan tanah, derajat kejenuhan.

\section{PENDAHULUAN}

Hal yang terpenting dalam dunia konstruksi terutama pada pekerjaan yang berhubungan dengan penggalian dan penimbunan tanah yaitu merupakan kestabilan dari galian dan timbunan tanah. Hal ini dapat berpengaruh terhadap keselamatan manusia dan kekuatan konstruksi yang akan di bangun.

Dalam bidang konstruksi hal-hal yang perlu diperhatikan untuk pembuatan galian yaitu kestabilan dari galian yang dipengaruhi oleh tekanan tanah, kedalaman galian, jenis tanah, kondisi di sekitar galian, jenis dinding penahan tanah yang dipakai, dan lain-lain. Selain itu tanah memiliki sifat karakter yang berbeda-beda seperti ikatan partikel penyusun tanah, kadar air, dan lain-lain. Porositas tanah adalah kemampuan tanah dalam menyerap air yang berkaitan dengan kepadatan tanah. Semakin padat tanah berarti akan semakin sulit untuk menyerap air, maka porositas tanah semakin kecil. Sebaliknya semakin mudah tanah menyerap air maka tanah tersebut memiliki porositas yang besar. Penurunan kepadatan tanah akan menyebabkan gaya tarik antara partikel padat tanah semakin berkurang dan kecenderungan partikel padat untuk tergelincir atau longsor semakin meningkat.

Untuk mencegah tanah yang longsor maka dibutuhkan dinding penahan tanah untuk menahan beban lateral serta menyokong tekanan tanah dan air, metode yang telah dikembangkan sebagai perkuatan untuk dinding penahan tanah salah satunya yaitu adalah ground anchor yang dapat berfungsi untuk menahan beban lateral dari timbunan tanah di belakang dinding penahan tanah.

Pada saat proses perencanaan dinding penahan tanah dengan perkuatan ground anchor, maka kapasitas tarik dari ground anchor perlu diperhatikan agar sesuai dan dapat menahan perubahan dari gaya tarik antara partikel padat tanah. Selain hal itu, perlu diperhatikan pada saat metode pelaksanaan konstruksinya, sehingga tidak terjadi keruntuhan akibat adanya kelalaian dari metode pelaksanaan konstruksi dilapangan.

\section{Batasan Masalah}

- Penentuan parameter tanah yang digunakan di ambil dari data tanah di wilayah Pulau Jawa.

- Kondisi tanah dengan keadaan kondisi in-situ dan jenuh. 
- Penentuan jenis, material, dan panjang dinding penahan tanah.

- Penentuan faktor keamanan sesuai dengan penggunaan ground anchor dan dimensi dinding penahan tanah.

- Penentuan kapasitas tarik ground anchor.

- Tidak ada penuruhan muka air tanah akibat galian, dan tidak terjadi basal heave dan uplift pressure saat penggalian tanah.

- Tidak memperhitungkan struktural dari dinding penahan tanah.

- Tidak memperhitungkan gempa.

\section{Tujuan Penelitian}

- Mengetahui stabilitas pada ground anchor dan dinding penahan tanah yang disebabkan air tanah dan dorongan tanah.

- Mengetahui perbedaan keamanan ground anchor pada saat kondisi tanah in-situ dan jenuh.

- Mengidentifikasi apakah ada keruntuhan ground anchor yang terjadi akibat metode pelaksanaan konstruksi di lapangan.

\section{TINJAUAN PUSTAKA}

Menurut Xanthakos (1990) komponen pada ground anchor meliputi head anchor, free length anchor, dan bond length anchor seperti pada gambar 1 . Bond length anchor adalah bagian dari tendon yang terjauh dikelilingi oleh grouting (material semen) dimana gaya tarik dipindahkan ke tanah disekitar jangkar. Free length anchor adalah tendon bagian atas dimana tidak ada gaya tarik yang dipindahkan ke tanah disekitar jangkar, dan dapat bebas bergerak selama interaksi tanah dan jangkar terjadi, sehingga dapat terjadi elongation. Head anchor merupakan komponen jangkar yang dapat memindahkan beban tarik dari jangkar ke permukaan tanah atau struktur. Sehingga ground anchor dapat berfungsi untuk menahan beban lateral dari timbunan tanah di belakang dinding penahan tanah. Ground anchor adalah elemen struktural yang dipasang pada tanah atau batu yang digunakan untuk mentransmisikan beban tarik yang diterapkan ke dalam tanah. Sistem ground anchor di bagi menjadi dua, yaitu penjangkaran aktif dan pasif. Penjangkaran aktif disebut prestressed yaitu gaya awal yang diberikan pada struktur sehingga gaya tersebut menahan interaksi antara tanah dan struktur. Penjangkaran pasif disebut dead yaitu gaya yang bereaksi terhadap pembebanan ketika struktur yang di dukung mulai aktif.

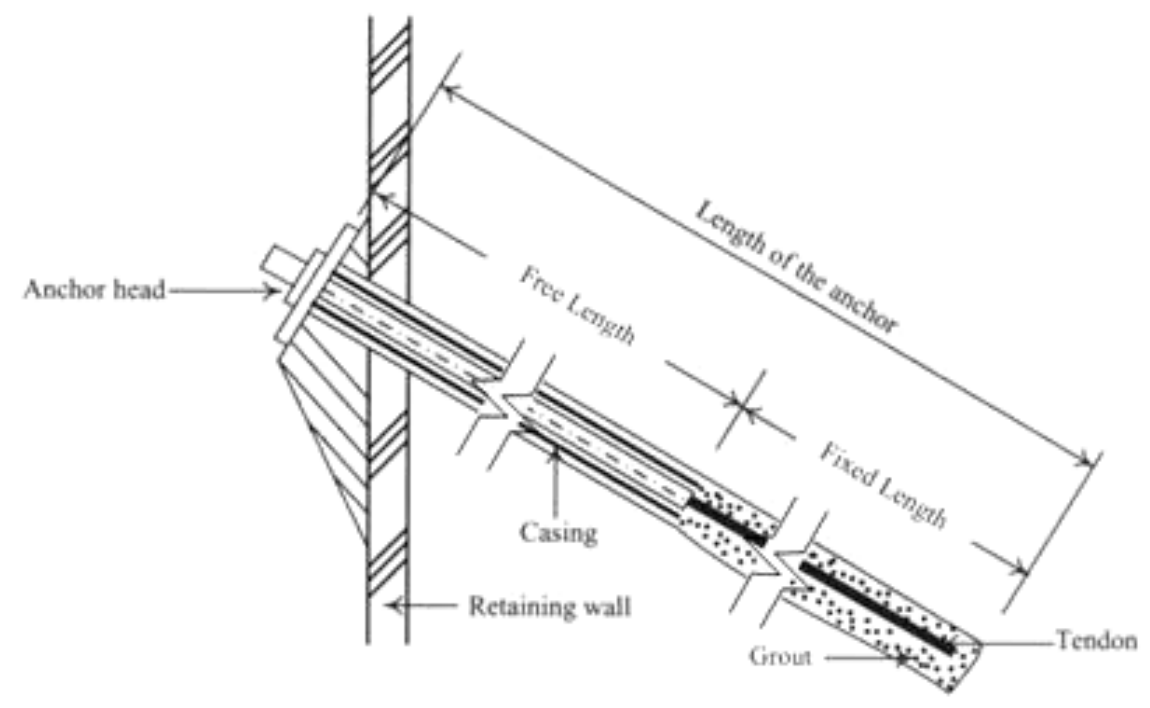

Gambar 1. Komponen Ground Anchor

\section{METODOLOGI PENELITIAN}

Dalam penelitian ini dilakukan beberapa tahapan yang dapat diuraikan sebagai berikut:

Tahapan pertama adalah melakukan pengumpulan data berupa data tanah (hasil tes boring dan hasil korelasi), data ground anchor (kapasitas tarik angkur, panjang bond length) dan buku referensi maupun jurnal yang terkait.

Tahapan kedua adalah melakukan perencanaan galian dan pemasangan angkur untuk setiap galian pada kondisi tanah in-situ dan jenuh, serta rencana keadaan muka air tanah. 
Tahapan ketiga adalah melakukan analisis perhitungan tekanan tanah aktif dan pasif terhadap dinding penahan tanah dengan ground anchor yang kemudian ditetapkan sebagai faktor keamanan $\geq 1.5$ untuk guling, geser, dan daya dukung tanah.

Tahapan keempat adalah melakukan analisis perhitungan untuk pengecekan defleksi yang dialami oleh dinding penahan tanah, dan batas ijin berdasarkan aturan SNI Geoteknik 8460:2017, serta batas dari kekuatan penampang dinding penahan tanah untuk mengalami defleksi yang terjadi.

Tahapan kelima adalah melakukan perhitungan untuk panjang bond length untuk spesifikasi ground anchor, dan menarik kesimpulan berdasarkan hasil analisis yang telah dilakukan.

\section{ANALISIS DAN PEMBAHASAN}

Analisis dilakukan berdasarkan data tanah yang diperoleh pada suatu proyek di wilayah Pulau Jawa, seperti pada tabel 1.

Tabel 1. Data tanah

\begin{tabular}{|c|c|c|c|c|c|c|c|c|c|c|}
\hline \multirow[b]{2}{*}{$\begin{array}{l}\text { DEPTH } \\
\quad(\mathrm{m})\end{array}$} & \multirow[b]{2}{*}{ SOIL DESCRIPTION } & \multirow[b]{2}{*}{$\begin{array}{l}\text { N-SPT } \\
\text { (blows/ft) }\end{array}$} & \multicolumn{4}{|c|}{ Strength Test } & \multicolumn{3}{|c|}{ Atterberg Limits } & \multirow[b]{2}{*}{$\begin{array}{c}\gamma \\
\left(\mathrm{kN} / \mathrm{m}^{3}\right)\end{array}$} \\
\hline & & & Type & $\begin{array}{c}\mathrm{C} \\
\left(\mathrm{kg} / \mathrm{cm}^{2}\right)\end{array}$ & $\begin{array}{l}\phi \\
\left({ }^{\circ}\right)\end{array}$ & $\underset{\left(\mathrm{t} / \mathrm{m}^{2}\right)}{\mathrm{Cu}}$ & $\begin{array}{l}\text { Wn } \\
(\%)\end{array}$ & $\begin{array}{l}\mathrm{Wp} \\
(\%)\end{array}$ & $\begin{array}{l}\mathrm{Wt} \\
(\%)\end{array}$ & \\
\hline 1 & $\begin{array}{c}\text { Clay and silt, } \\
\text { brownish grey, little to } \\
\text { some fine sand, soft }\end{array}$ & 2 & QT & 0.3 & 21 & 1.85 & 58 & 26 & 42 & 1.4 \\
\hline 3.5 & $\begin{array}{c}\text { Fine sand and silt, } \\
\text { brownish grey, loose }\end{array}$ & 4 & - & - & - & - & - & - & - & - \\
\hline 5 & $\begin{array}{c}\text { Fine sand, dark grey, } \\
\text { little silt, loose }\end{array}$ & 5 & - & - & - & - & - & - & - & - \\
\hline 7 & $\begin{array}{l}\text { Clay and silt, grey, } \\
\text { trace sand, very soft }\end{array}$ & 0 & UU & 0.16 & 8 & 1.197 & 83 & 25 & 46 & 1.4 \\
\hline 11 & $\begin{array}{l}\text { Fine sand and silt, } \\
\text { grey, medium }\end{array}$ & 7 & - & - & - & - & - & - & - & - \\
\hline 12.5 & $\begin{array}{c}\text { Fine sand, brown to } \\
\text { grey, little silt, very } \\
\text { dense }\end{array}$ & 42 & - & - & - & - & - & - & - & - \\
\hline 15.5 & $\begin{array}{l}\text { Clay and silt, } \\
\text { yellowish brown with } \\
\text { grey, trace sand, very } \\
\text { stiff }\end{array}$ & 17 & - & - & - & - & - & - & - & - \\
\hline 20 & $\begin{array}{c}\text { Clay and silt, grey, } \\
\text { inorganic, trace sand, } \\
\text { very stiff }\end{array}$ & 18 & - & - & - & - & - & - & - & - \\
\hline 21 & $\begin{array}{c}\text { Clay and silt, } \\
\text { yellowish brown, trace } \\
\text { to little fine sand, very } \\
\text { stiff }\end{array}$ & 19 & - & - & - & - & - & - & - & - \\
\hline 26 & $\begin{array}{l}\text { Silt and fine sand, } \\
\text { brown, dense }\end{array}$ & 28 & - & - & - & - & - & - & - & - \\
\hline 28 & $\begin{array}{c}\text { Clay and silt, } \\
\text { brownish grey, } \\
\text { inorganic, trace to } \\
\text { little fine sand, very } \\
\text { stiff }\end{array}$ & 24 & - & - & - & - & - & - & - & - \\
\hline 30 & $\begin{array}{l}\text { Clay and silt, grey, } \\
\text { trace sand, very stiff }\end{array}$ & 20 & - & - & - & - & - & - & - & - \\
\hline 50 & End of boring & & & & & & & & & \\
\hline
\end{tabular}

Kemudian dikorelasikan menjadi keadaan kondisi tanah in-situ dan mendapatkan parameter-parameter tanah yang dibutuhkan untuk dilakukan analisis perhitungan, seperti pada tabel 2. 
Tabel 2. Data tanah korelasi in-situ

\begin{tabular}{|c|c|c|c|c|c|c|c|c|c|c|}
\hline \multirow{2}{*}{$\begin{array}{l}\text { DEPTH } \\
\text { (m) }\end{array}$} & \multirow[b]{2}{*}{ SOIL DESCRIPTION } & \multirow{2}{*}{$\begin{array}{l}\text { N-SPT } \\
\text { (blows/ft) }\end{array}$} & \multicolumn{4}{|c|}{ Strength Test } & \multicolumn{3}{|c|}{ Atterberg Limits } & \multirow[b]{2}{*}{$\begin{array}{c}\gamma \\
\left(\mathrm{kN} / \mathrm{m}^{3}\right.\end{array}$} \\
\hline & & & Tyре & $\begin{array}{c}\mathrm{C} \\
\left(\mathrm{kg} / \mathrm{cm}^{2}\right) \\
\end{array}$ & $\begin{array}{l}\phi \\
\left({ }^{\circ}\right)\end{array}$ & $\begin{array}{c}\mathrm{Cu} \\
\left(\mathrm{t} / \mathrm{m}^{2}\right)\end{array}$ & $\begin{array}{l}\text { Wn } \\
(\%)\end{array}$ & $\begin{array}{l}\text { Wp } \\
(\%)\end{array}$ & $\begin{array}{l}\text { Wt } \\
(\%)\end{array}$ & \\
\hline 1 & $\begin{array}{c}\text { Clay and silt, } \\
\text { brownish grey, little to } \\
\text { some fine sand, soft }\end{array}$ & 2 & QT & 0.3 & 21 & 1.85 & 58 & 26 & 42 & 1.4 \\
\hline 3.5 & $\begin{array}{l}\text { Fine sand and silt, } \\
\text { brownish grey, loose }\end{array}$ & 4 & - & 0 & 28 & - & - & - & - & 1.36 \\
\hline 5 & $\begin{array}{l}\text { Fine sand, dark grey, } \\
\text { little silt, loose }\end{array}$ & 5 & - & 0 & 29 & - & - & - & - & 1.4 \\
\hline 7 & $\begin{array}{l}\text { Clay and silt, grey, } \\
\text { trace sand, very soft }\end{array}$ & 0 & UU & 0.16 & 8 & 1.197 & 83 & 25 & 46 & 1.4 \\
\hline 11 & $\begin{array}{l}\text { Fine sand and silt, } \\
\text { grey, medium }\end{array}$ & 7 & - & 0 & 30 & - & - & - & - & 1.48 \\
\hline 12.5 & $\begin{array}{l}\text { Fine sand, brown to } \\
\text { grey, little silt, very } \\
\text { dense }\end{array}$ & 42 & - & 0 & 37 & - & - & - & - & 1.832 \\
\hline 15.5 & $\begin{array}{l}\text { Clay and silt, } \\
\text { yellowish brown with } \\
\text { grey, trace sand, very } \\
\text { stiff }\end{array}$ & 17 & - & 1.11 & 32 & 2.39 & 58 & 34 & 68 & 1.64 \\
\hline 20 & $\begin{array}{c}\text { Clay and silt, grey, } \\
\text { inorganic, trace sand, } \\
\text { very stiff }\end{array}$ & 18 & - & 1.175 & 33 & 2.533 & 62 & 36 & 73 & 1.69 \\
\hline 21 & $\begin{array}{l}\text { Clay and silt, } \\
\text { yellowish brown, trace } \\
\text { to little fine sand, very } \\
\text { stiff }\end{array}$ & 19 & - & 1.24 & 34 & 2.67 & 63 & 38 & 74 & 1.73 \\
\hline 26 & $\begin{array}{l}\text { Silt and fine sand, } \\
\text { brown, dense }\end{array}$ & 28 & - & 0 & 35 & - & - & - & - & 1.758 \\
\hline 28 & $\begin{array}{c}\text { Clay and silt, } \\
\text { brownish grey, } \\
\text { inorganic, trace to } \\
\text { little fine sand, very } \\
\text { stiff }\end{array}$ & 24 & - & 1.566 & 36 & 3.33 & 72 & 42 & 84 & 1.956 \\
\hline 30 & $\begin{array}{l}\text { Clay and silt, grey, } \\
\text { trace sand, very stiff }\end{array}$ & 20 & - & 1.3 & 34 & 2.8 & 67 & 40 & 78 & 1.778 \\
\hline 50 & End of boring & & & & & & & & & \\
\hline
\end{tabular}

Keterangan: '-‘ = not applicable

Kemudian dikorelasikan menjadi keadaan kondisi tanah jenuh dan mendapatkan parameter-parameter tanah yang dibutuhkan untuk dilakukan analisis perhitungan, seperti pada tabel 3.

Tabel 3. Data tanah korelasi jenuh

\begin{tabular}{|c|c|c|c|c|c|c|c|c|c|c|}
\hline \multirow{2}{*}{$\begin{array}{c}\text { DEPTH } \\
\text { (m) }\end{array}$} & \multirow[b]{2}{*}{ SOIL DESCRIPTION } & \multirow{2}{*}{$\begin{array}{l}\text { N-SPT } \\
\text { (blows/ft) }\end{array}$} & \multicolumn{4}{|c|}{ Strength Test } & \multicolumn{3}{|c|}{ Atterberg Limits } & \multirow[b]{2}{*}{$\begin{array}{c}\gamma \\
\left(\mathrm{kN} / \mathrm{m}^{3}\right)\end{array}$} \\
\hline & & & Type & $\begin{array}{c}\mathrm{C} \\
\left(\mathrm{kg} / \mathrm{cm}^{2}\right)\end{array}$ & $\begin{array}{l}\phi \\
\left({ }^{\circ}\right)\end{array}$ & $\underset{\left(\mathrm{t} / \mathrm{m}^{2}\right)}{\mathrm{Cu}}$ & $\begin{array}{l}\text { Wn } \\
(\%)\end{array}$ & $\begin{array}{l}\mathrm{Wp} \\
(\%)\end{array}$ & $\begin{array}{l}\mathrm{Wt} \\
(\%)\end{array}$ & \\
\hline 1 & $\begin{array}{c}\text { Clay and silt, brownish } \\
\text { grey, little to some fine } \\
\text { sand, soft }\end{array}$ & 2 & QT & 0.3 & 21 & 1.85 & 70 & 26 & 45 & 1.6 \\
\hline 3.5 & $\begin{array}{l}\text { Fine sand and silt, } \\
\text { brownish grey, loose }\end{array}$ & 4 & - & 0 & 28 & - & - & - & - & 1.53 \\
\hline 5 & $\begin{array}{l}\text { Fine sand, dark grey, } \\
\text { little silt, loose }\end{array}$ & 5 & - & 0 & 29 & - & - & - & - & 1.67 \\
\hline 7 & $\begin{array}{l}\text { Clay and silt, grey, } \\
\text { trace sand, very soft }\end{array}$ & 0 & UU & 0.16 & 8 & 1.197 & 90 & 25 & 29 & 1.6 \\
\hline
\end{tabular}


Lanjutan tabel 3.

\begin{tabular}{|c|c|c|c|c|c|c|c|c|c|c|}
\hline \multirow{2}{*}{$\begin{array}{l}\text { DEPTH } \\
\quad(\mathrm{m})\end{array}$} & \multirow[b]{2}{*}{ SOIL DESCRIPTION } & \multirow{2}{*}{$\begin{array}{l}\text { N-SPT } \\
\text { (blows/ft) }\end{array}$} & \multicolumn{4}{|c|}{ Strength Test } & \multicolumn{3}{|c|}{ Atterberg Limits } & \multirow[b]{2}{*}{$\begin{array}{c}\gamma \\
\left(\mathrm{kN} / \mathrm{m}^{3}\right)\end{array}$} \\
\hline & & & Type & $\begin{array}{c}\mathrm{C} \\
\left(\mathrm{kg} / \mathrm{cm}^{2}\right) \\
\end{array}$ & $\begin{array}{l}\phi \\
\left({ }^{\circ}\right)\end{array}$ & $\underset{\left(t / m^{2}\right)}{\mathrm{Cu}}$ & $\begin{array}{l}\text { Wn } \\
(\%)\end{array}$ & $\begin{array}{l}\text { Wp } \\
(\%)\end{array}$ & $\begin{array}{l}\mathrm{Wt} \\
(\%)\end{array}$ & \\
\hline 11 & $\begin{array}{l}\text { Fine sand and silt, grey, } \\
\text { medium }\end{array}$ & 7 & - & 0 & 30 & - & - & - & - & 1.7 \\
\hline 12.5 & $\begin{array}{c}\text { Fine sand, brown to } \\
\text { grey, little silt, very } \\
\text { dense }\end{array}$ & 42 & - & 0 & 37 & - & - & - & - & 2.3 \\
\hline 15.5 & $\begin{array}{l}\text { Clay and silt, yellowish } \\
\text { brown with grey, trace } \\
\text { sand, very stiff }\end{array}$ & 17 & - & 1.11 & 32 & 2.39 & 72 & 34 & 70 & 1.94 \\
\hline 20 & $\begin{array}{c}\text { Clay and silt, grey, } \\
\text { inorganic, trace sand, } \\
\text { very stiff }\end{array}$ & 18 & - & 1.175 & 33 & 2.533 & 78 & 36 & 75 & 1.96 \\
\hline 21 & $\begin{array}{l}\text { Clay and silt, yellowish } \\
\text { brown, trace to little } \\
\text { fine sand, very stiff }\end{array}$ & 19 & - & 1.24 & 34 & 2.67 & 79 & 38 & 78 & 1.98 \\
\hline 26 & $\begin{array}{l}\text { Silt and fine sand, } \\
\text { brown, dense }\end{array}$ & 28 & - & 0 & 35 & - & - & - & - & 2.129 \\
\hline 28 & $\begin{array}{l}\text { Clay and silt, brownish } \\
\text { grey, inorganic, trace to } \\
\text { little fine sand, very stiff }\end{array}$ & 24 & - & 1.566 & 36 & 3.33 & 85 & 42 & 88 & 2.08 \\
\hline 30 & $\begin{array}{l}\text { Clay and silt, grey, } \\
\text { trace sand, very stiff }\end{array}$ & 20 & - & 1.3 & 34 & 2.8 & 83 & 40 & 82 & 2 \\
\hline 50 & End of boring & & & & & & & & & \\
\hline
\end{tabular}

Keterangan: ‘-‘ = not applicable

\section{Tekanan tanah aktif dan pasif}

Pada dinding penahan tanah yang telah dipasang ke dalam tanah akan mengalami gaya lateral berupa tekanan tanah aktif dan tekanan tanah pasif. Pada perhitungan tekanan tanah aktif dan pasif menggunakan teori Rankine. Untuk perhitungan tekanan tanah aktif dan pasif pada tanah non-kohesif dengan persamaan:

$$
\begin{gathered}
P a=\frac{1}{2} \cdot \gamma \cdot H^{2} \cdot K a \\
K a=\tan ^{2}\left(45^{\circ}-\frac{\phi}{2}\right) \\
P p=\frac{1}{2} \cdot \gamma \cdot H^{2} \cdot K p \\
K p=\tan ^{2}\left(45^{\circ}+\frac{\phi}{2}\right)
\end{gathered}
$$

Untuk perhitungan tekanan tanah aktif dan pasif pada tanah kohesif dengan persamaan:

$$
\begin{gathered}
P a=\frac{1}{2} \cdot \gamma \cdot H^{2} \cdot K a \pm 2 \cdot c \cdot H \cdot \sqrt{K a} \\
K a=\tan ^{2}\left(45^{\circ}-\frac{\phi}{2}\right)-\frac{2 c}{\sigma_{v}} \tan \left(45^{\circ}-\frac{\phi}{2}\right) \\
P p=\frac{1}{2} \cdot \gamma \cdot H^{2} \cdot K a \pm 2 \cdot c \cdot H \cdot \sqrt{K p}
\end{gathered}
$$




$$
K p=\tan ^{2}\left(45^{\circ}+\frac{\phi}{2}\right)+\frac{2 c}{\sigma_{v}} \tan \left(45^{\circ}+\frac{\phi}{2}\right)
$$

Dengan $\mathrm{Pa}=$ tekanan tanah aktif, $\mathrm{Pp}=$ tekanan tanah pasif, $\gamma=$ berat jenis tanah, $\mathrm{H}=$ tinggi lapisan, Ka $=$ koefisien tekanan tanah aktif, $\mathrm{Kp}=$ koefisien tekanan tanah pasif, $\phi=$ sudut geser dalam, $\mathrm{c}=$ kohesi tanah, dan $\sigma_{\mathrm{V}}=$ tegangan efektif tanah.

\section{Analisis stabilitas terhadap guling, geser, dan daya dukung}

Analisis stabilitas dinding penahan tanah dengan ground anchor menggunakan pengecekan terhadap guling, geser dan daya dukung tanah $\geq 1.5$, hal ini dikarenakan adanya faktor potensi yang diperhatikan pada dinding penahan tanah secara keseluruhan mengalami gelincir rotasi atau translasi (global stability).

$$
\begin{aligned}
& S F=\frac{\sum M b}{\sum M o} \geq 1.5 \\
& S F=\frac{\sum V b}{\sum V o} \geq 1.5 \\
& S F=\frac{q u}{\sigma} \geq 1.5
\end{aligned}
$$

Dengan $\mathrm{Mb}=$ momen penahan, $\mathrm{Mo}=$ momen pengguling, $\mathrm{Vb}=$ gaya penahan, $\mathrm{Vo}=$ gaya penggeser, $\mathrm{qu}=$ kapasitas maksimum daya dukung tanah dan $\sigma=$ daya dukung ijin.

\section{Kapasitas tarik angkur}

Kapasitas tarik angkur dapat ditentukan dengan menggunakan formula berdasarkan Canadian Foundation Engineering Manual.

Kapasitas tarik dari fixed length yang terbenam pada tanah kohesif ditentukan dengan persamaan:

$$
T_{\text {ult }}=\alpha \cdot A_{s} \cdot L_{s} \cdot S_{u}
$$

Dengan $\mathrm{T}_{\text {ult }}=$ kapasitas batas angkur tanah, $\alpha=$ faktor adhesi tergantung pada kuat geser tak terdrainase tanah, $\mathrm{A}_{\mathrm{s}}=$ luas selimut fixed length, $\mathrm{L}_{\mathrm{s}}=$ panjang fixed length, dan $\mathrm{S}_{\mathrm{u}}=$ kuat geser tak terdrainase tanah rata-rata sepanjang fixed length (0.45-0.75).

Kapasitas tarik dari fixed length yang terbenam pada tanah non-kohesif ditentukan dengan persamaan:

$$
T_{\text {ult }}=\sigma_{v} \cdot A_{s} \cdot L_{s} \cdot K_{s}
$$

Dengan $K_{s}=$ koefisien angkur tergantung pada tipe dan kepadatan tanah non-kohesif seperti pada tabel 4.

Tabel 4. Koefisien angkur $\mathrm{K}_{\mathrm{s}}$ Canadian Foundation Engineering Manual (SNI Geoteknik 8460:2017)

\begin{tabular}{cccc}
\hline \multirow{2}{*}{ Tipe Tanah } & \multicolumn{3}{c}{ Kepadatan Tanah } \\
\cline { 2 - 4 } & Lepas (loose) & Kompak (compact) & Padat (dense) \\
\hline Lanau non-plastis & 0.1 & 0.4 & 1 \\
\hline Pasir halus & 0.2 & 0.6 & 1.5 \\
\hline Medium sand & 0.5 & 1.2 & 3 \\
\hline Pasir kasar, kerikil & 1 & 2 & 3
\end{tabular}

\section{Defleksi akibat momen crack}

Batas defleksi yang dapat mampu ditahan oleh dinding penahan tanah, dianggap jepit bebas dengan persamaan:

$$
\Delta=\frac{P L^{3}}{3 \cdot E I}
$$


Dengan $\Delta=$ defleksi, $\mathrm{P}=$ gaya akibat momen crack, $\mathrm{L}=$ kedalaman dinding penahan tanah, $\mathrm{E}=$ modulus elastisitas, $\mathrm{I}=$ inersia penampang.

Dengan momen crack yang terjadi pada dinding penahan tanah ditentukan dengan persamaan:

$$
\begin{gathered}
M_{\text {crack }}=\frac{I_{g} \cdot f_{r}}{y_{t}} \\
f_{r}=0.63 \sqrt{f^{\prime}{ }_{c}}
\end{gathered}
$$

Dengan $\mathrm{M}_{\text {crack }}=$ momen crack penampang, $\mathrm{I}_{\mathrm{g}}=$ inersia gross penampang, $f_{\mathrm{r}}=$ modulus rupture, $f_{c}{ }_{c}=$ mutu beton, $y_{t}=$ jarak serat tarik terluar ke pusat penampang $\left(\frac{h}{2}\right.$ untuk penampang segiempat).

\section{HASIL ANALISIS}

Untuk analisis direncanakan jenis dinding penahan tanah yang digunakan yaitu diaphragm wall dengan tebal 0.8 meter, kedalaman 20 meter dan $f_{c}{ }_{c} 25$ MPa. Dengan rencana galian 3 basement masing-masing kedalaman 4 meter, dengan beberapa rencana pemasangan angkur disetiap galian basement.

Berdasarkan analisis yang dilakukan maka diambil sampel pada kondisi galian basement tiga lapis dengan 3 buah angkur dengan kondisi muka air tanah normal seperti pada gambar 1, serta kondisi galian basement tiga lapis tanpa angkur dengan kondisi muka air tanah normal, kondisi muka air tanah pada galian, dan kondisi tanpa adanya air seperti pada gambar 2.

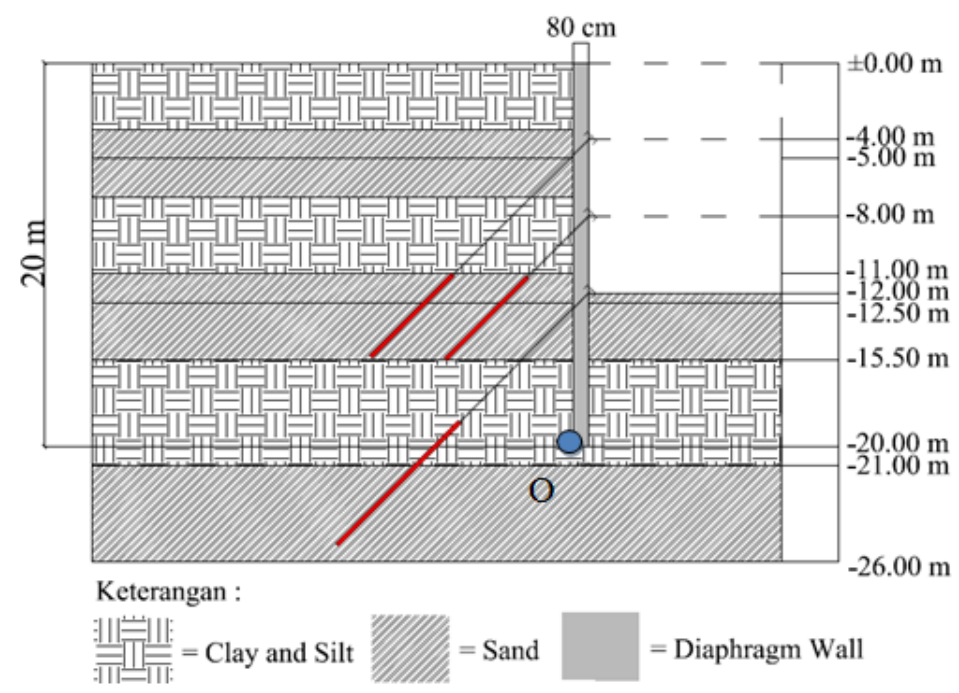

Gambar 1. Galian tiga lapis basement dipasangkan 3 buah angkur

Berikut merupakan hasil stabilitas dinding penahan tanah terhadap guling, geser, dan daya dukung untuk galian tiga lapis basement dipasangkan 3 buah angkur untuk kondisi tanah in-situ dan jenuh yang ditinjau pada titik O seperti pada tabel 5.

Tabel 5. Hasil Perhitungan Safety Factor Kondisi In-situ dan Jenuh Kedalaman 12 meter (Dengan 3 Angkur)

\begin{tabular}{cccc}
\hline Rencana Galian & Pengecekan & $\begin{array}{c}\text { Safety } \\
\text { Factor }\end{array}$ & $\begin{array}{c}\text { Aman/Tidak } \\
\text { Aman }\end{array}$ \\
\hline \multirow{2}{*}{$\begin{array}{c}\text { Kondisi in-situ kedalaman 12 meter (dengan 3 angkur) } \\
\text { muka air tanah normal }\end{array}$} & Cek terhadap guling & 1.5016 & $v$ \\
\cline { 2 - 4 } & Cek terhadap geser & 2.3273 & $v$ \\
\cline { 2 - 4 } $\begin{array}{c}\text { Cek terhadap daya } \\
\text { dukung tanah }\end{array}$ & 0.0429 & $x$ \\
\hline \multirow{2}{*}{$\begin{array}{c}\text { Cek terhadap guling } \\
\text { Kondisi jenuh kedalaman 12 meter (dengan 3 angkur) } \\
\text { muka air tanah normal }\end{array}$} & 1.46026 & $x$ \\
\cline { 2 - 4 } & $\begin{array}{c}\text { Cek terhadap geser } \\
\text { Cek terhadap daya } \\
\text { dukung tanah }\end{array}$ & 0.05038 & $\mathrm{x}$ \\
\cline { 2 - 4 } & & & \\
\hline
\end{tabular}

Keterangan: ' $v{ }^{\natural}=\geq 1.5$ (aman); ' $x$ ' $=\leq 1.5$ (tidak aman) 


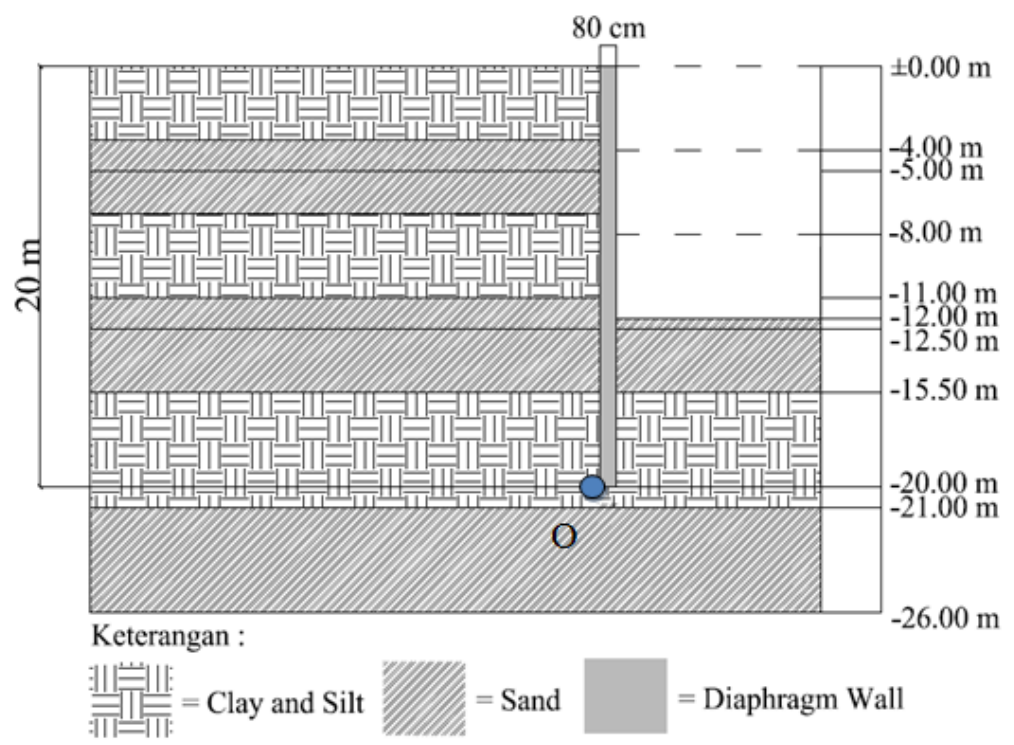

Gambar 2. Galian tiga lapis basement tanpa angkur

Berikut merupakan hasil stabilitas dinding penahan tanah terhadap guling, geser, dan daya dukung untuk galian tiga lapis basement tanpa angkur untuk kondisi tanah in-situ dan jenuh untuk muka air tanah normal, muka air tanah pada galian, dan tanpa adanya air yang ditinjau pada titik O seperti pada tabel 6.

Tabel 6. Hasil Perhitungan Safety Factor Kondisi In-situ dan Jenuh Kedalaman 12 meter (Tanpa Angkur) Dengan 3 Kondisi Muka Air Tanah

\begin{tabular}{|c|c|c|c|}
\hline Rencana Galian & Pengecekan & $\begin{array}{l}\text { Safety } \\
\text { Factor }\end{array}$ & $\begin{array}{l}\text { Aman/Tidak } \\
\text { Aman }\end{array}$ \\
\hline \multirow{3}{*}{$\begin{array}{l}\text { Kondisi in-situ kedalaman } 12 \text { meter (tanpa angkur) } \\
\text { muka air tanah normal }\end{array}$} & Cek terhadap guling & 0.04318 & $x$ \\
\hline & Cek terhadap geser & 1.98979 & $v$ \\
\hline & $\begin{array}{l}\text { Cek terhadap daya } \\
\text { dukung tanah }\end{array}$ & 0.00929 & $x$ \\
\hline \multirow{3}{*}{$\begin{array}{l}\text { Kondisi jenuh kedalaman } 12 \text { meter (tanpa angkur) } \\
\text { muka air tanah normal }\end{array}$} & Cek terhadap guling & 0.04199 & $x$ \\
\hline & Cek terhadap geser & 2.02775 & $v$ \\
\hline & $\begin{array}{l}\text { Cek terhadap daya } \\
\text { dukung tanah }\end{array}$ & 0.01127 & $x$ \\
\hline \multirow{3}{*}{$\begin{array}{l}\text { Kondisi in-situ kedalaman } 12 \text { meter (tanpa angkur) } \\
\text { muka air tanah pada galian }\end{array}$} & Cek terhadap guling & -1.8201 & $x$ \\
\hline & Cek terhadap geser & 6.71035 & $v$ \\
\hline & $\begin{array}{l}\text { Cek terhadap daya } \\
\text { dukung tanah }\end{array}$ & 0.002066 & $x$ \\
\hline \multirow{3}{*}{$\begin{array}{l}\text { Kondisi jenuh kedalaman } 12 \text { meter (tanpa angkur) } \\
\text { muka air tanah pada galian }\end{array}$} & Cek terhadap guling & -1.90478 & $x$ \\
\hline & Cek terhadap geser & 5.61179 & $v$ \\
\hline & $\begin{array}{l}\text { Cek terhadap daya } \\
\text { dukung tanah }\end{array}$ & 0.02038 & $x$ \\
\hline \multirow{3}{*}{$\begin{array}{c}\text { Kondisi in-situ kedalaman } 12 \text { meter (tanpa angkur) } \\
\text { tanpa air }\end{array}$} & Cek terhadap guling & -1.8201 & $x$ \\
\hline & Cek terhadap geser & 6.71035 & $v$ \\
\hline & $\begin{array}{l}\text { Cek terhadap daya } \\
\text { dukung tanah }\end{array}$ & 0.002066 & $x$ \\
\hline
\end{tabular}

Keterangan: ' $v$ ' $=\geq 1.5$ (aman); ' $x$ ' $=\leq 1.5$ (tidak aman)

Kemudian dilakukan perhitungan defleksi yang dialami oleh dinding penahan tanah akibat dari tekanan tanah, tekanan air, pada rencana basement 12 meter tanpa angkur untuk kondisi in-situ dan jenuh dengan muka air tanah normal, muka air tanah pada galian, dan tanpa air, serta rencana basement 12 meter dengan 3 angkur pada muka air tanah normal seperti pada tabel 7.

Batas ijin defleksi dari dinding penahan tanah berdasarkan SNI Geoteknik 8460:2017 yaitu 0.5\%H, dimana H adalah kedalaman dinding penahan tanah. Dengan kedalaman dinding penahan tanah 20 meter, batas ijin defleksinya yaitu 0.1 meter dan berdasarkan hasil perhitungan batas defleksi yang mampu ditahan oleh penampang dinding penahan tanah akibat momen crack yaitu 0.03574 meter. 
Tabel 7. Hasil Perhitungan Defleksi pada Dinding Penahan Tanah Basement 12 meter Tanpa Angkur dan Dengan 3 Angkur

\begin{tabular}{|c|c|c|c|c|c|c|c|}
\hline \multirow{2}{*}{$\begin{array}{l}\text { Kedalaman } \\
\text { (m) }\end{array}$} & \multicolumn{5}{|c|}{$\begin{array}{c}\text { Defleksi pada } \\
\text { Dinding Penahan Tanah } \\
\text { Basement } 12 \text { meter (tanpa angkur) } \\
\text { (m) }\end{array}$} & \multicolumn{2}{|c|}{$\begin{array}{c}\text { Defleksi pada } \\
\text { Dinding Penahan } \\
\text { Tanah Basement } \\
12 \text { meter (dengan } 3 \\
\text { angkur) (m) } \\
\end{array}$} \\
\hline & $\begin{array}{l}\text { In-situ } \\
\text { (Muka } \\
\text { Air } \\
\text { Tanah } \\
\text { Normal) }\end{array}$ & $\begin{array}{l}\text { Jenuh } \\
\text { (Muka Air } \\
\text { Tanah } \\
\text { Normal) }\end{array}$ & $\begin{array}{c}\text { In-situ } \\
\text { (Muka Air } \\
\text { Tanah Pada } \\
\text { Galian) }\end{array}$ & $\begin{array}{c}\text { Jenuh } \\
\text { (Muka Air } \\
\text { Tanah Pada } \\
\text { Galian) }\end{array}$ & $\begin{array}{c}\text { In-situ } \\
\text { (Tanpa } \\
\text { Air) }\end{array}$ & In-situ & Jenuh \\
\hline 0 & -0.56 & -0.622 & -0.033 & -0.091 & 0.074 & -0.099 & -0.161 \\
\hline 3.5 & -0.44 & -0.487 & -0.028 & -0.072 & 0.059 & -0.083 & -0.13 \\
\hline 5 & -0.387 & -0.428 & -0.026 & -0.064 & 0.052 & -0.075 & -0.116 \\
\hline 7 & -0.316 & -0.349 & -0.021 & -0.052 & 0.045 & -0.063 & -0.096 \\
\hline 11 & -0.165 & -0.182 & -0.0073 & -0.023 & 0.036 & -0.024 & -0.041 \\
\hline 12.5 & -0.104 & -0.116 & -0.0015 & -0.012 & 0.033 & -0.001 & -0.012 \\
\hline 15.5 & -0.027 & 0.023 & -0.0006 & -0.022 & 0.023 & 0.068 & 0.064 \\
\hline 20 & 0 & 0 & 0 & 0 & 0 & 0 & 0 \\
\hline
\end{tabular}

Keterangan: nilai - = defleksi mengarah ke arah galian tanah; nilai + = defleksi mengarah ke arah timbunan tanah

Berikut disajikan berdasarkan tabel 7 hasil perhitungan defleksi yang dialami oleh dinding penahan tanah dalam bentuk grafik dibawah ini:

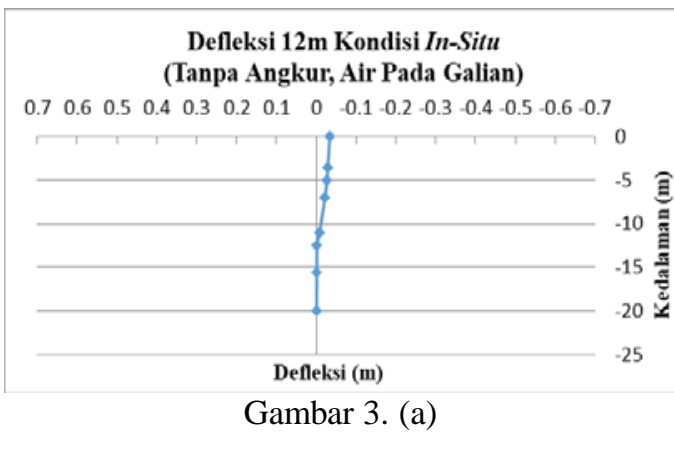

Defleksi $12 \mathrm{~m}$ Kondisi In-Situ (Tanpa Angkur)

$\begin{array}{lllllllllllllllllll}0.7 & 0.6 & 0.5 & 0.4 & 0.3 & 0.2 & 0.1-1 E-15 & 0.1 & -0.2 & -0.3 & -0.4 & -0.5 & -0.6 & -0.7\end{array}$

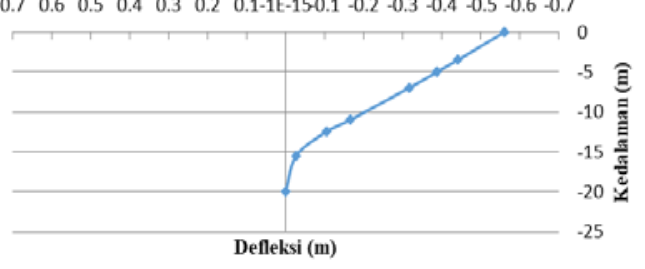

Gambar 5. (c)

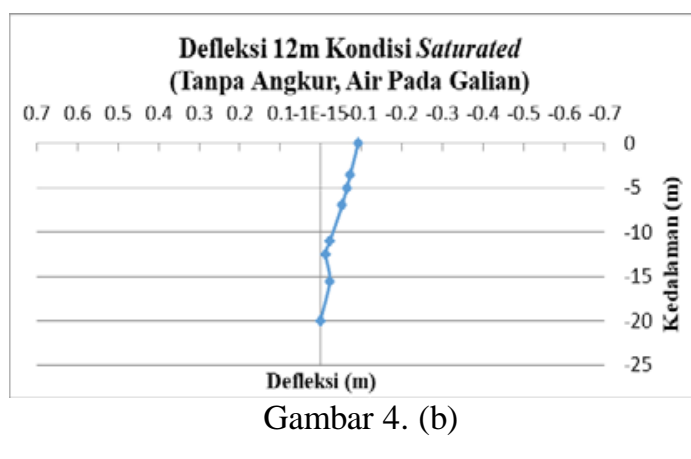

Defleksi $12 \mathrm{~m}$ Kondisi Saturated (Tanpa Angkur)

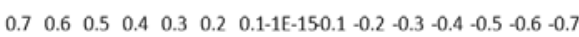

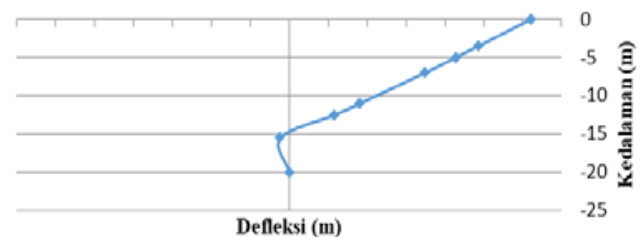

Gambar 6. (d)

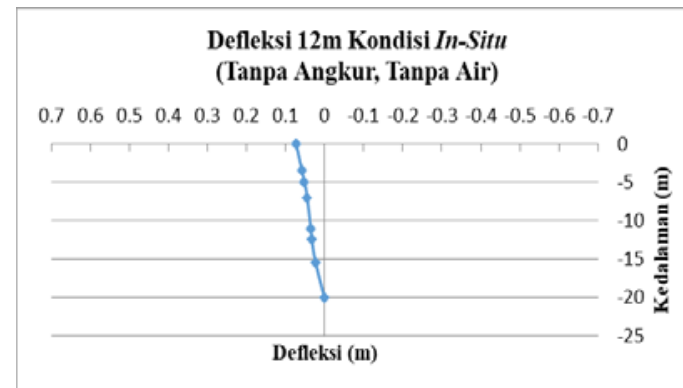

Gambar 7. (e) 


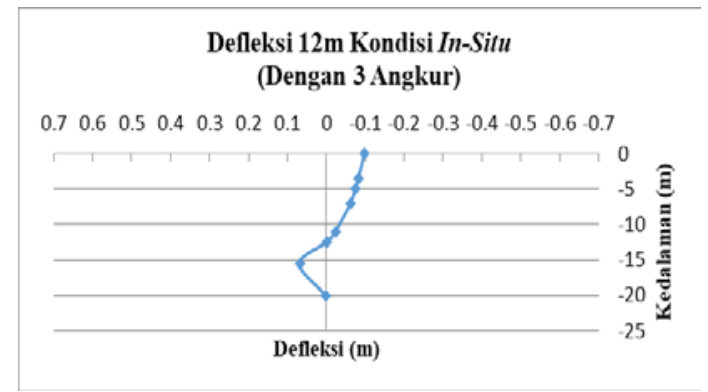

Gambar 8. (f)

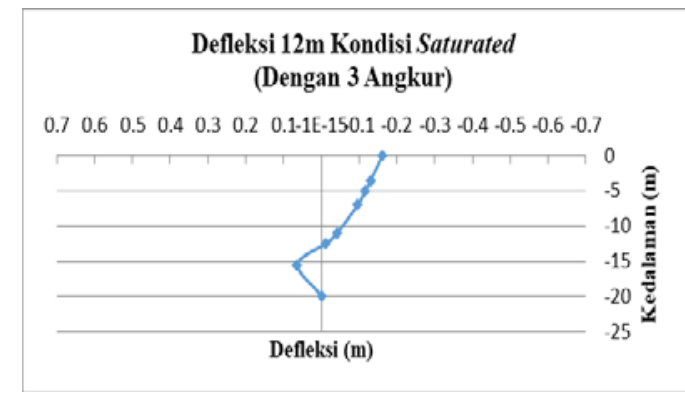

Gambar 9. (g)

Keterangan gambar:

(a). Defleksi pada galian basement tiga lapis tanpa angkur kondisi in-situ muka air tanah normal

(b). Defleksi pada galian basement tiga lapis tanpa angkur kondisi jenuh muka air tanah normal

(c). Defleksi pada galian basement tiga lapis tanpa angkur kondisi in-situ muka air tanah pada galian

(d). Defleksi pada galian basement tiga lapis tanpa angkur kondisi jenuh muka air tanah pada galian

(e). Defleksi pada galian basement tiga lapis tanpa angkur kondisi in-situ tanpa air

(f). Defleksi pada galian basement tiga lapis dengan 3 angkur kondisi in-situ muka air tanah normal

(g). Defleksi pada galian basement tiga lapis dengan 3 angkur kondisi jenuh muka air tanah normal

Setelah dilakukan analisis dan perhitungan didapat gaya tarik angkur sebesar 18.25 ton, maka dapat dihitung panjang dari bond length untuk spesifikasi ground anchor yang akan digunakan dengan rumus kapasitas tarik berdasarkan formula Canadian Foundation Engineering Manual, seperti pada tabel 12.

Tabel 12. Hasil Perhitungan Spesifikasi Ground Anchor

\begin{tabular}{ccc}
\hline Kedalaman Basement & $\begin{array}{c}\text { Panjang Free Length } \\
(\mathrm{m})\end{array}$ & $\begin{array}{c}\text { Panjang Bond Length } \\
(\mathrm{m})\end{array}$ \\
\hline Ground Anchor 1 $(4 \mathrm{~m})$ & 10 & 6 \\
\hline Ground Anchor 2 $(8 \mathrm{~m})$ & 4.5 & 6 \\
\hline Ground Anchor 3 $(12 \mathrm{~m})$ & 9.5 & 9 \\
\hline
\end{tabular}

\section{KESIMPULAN}

Dari hasil analisis dan perhitungan safety factor terhadap guling, geser, dan daya dukung tanah, serta perhitungan terhadap defleksi yang terjadi pada dinding penahan tanah, maka dapat ditarik kesimpulan sebagai berikut:

1. Kondisi jenuh lebih membutuhkan gaya tarik angkur yang lebih besar dibandingkan dengan gaya tarik angkur pada kondisi in-situ.

2. Dimensi dari dinding penahan tanah yang digunakan dapat mempengaruhi defleksi yang terjadi akibat dorongan tanah aktif dan pasif.

3. Proses pelaksanaan konstruksi galian per galian yang kemudian dipasangkan ground anchor lebih baik dibandingkan dengan proses pelaksanaan konstruksi yang digali secara langsung kemudian dipasangkan ground anchor karena jika digali secara langsung maka dinding penahan tanah akan langsung mengalami defleksi yang mengarah ke arah galian.

4. Kondisi keberadaan muka air tanah berpengaruh terhadap tekanan tanah yang terjadi, hal ini dibuktikan pada galian dengan tiga lapis basement dengan tiga jenis kondisi muka air tanah, saat kondisi muka air tanah normal defleksi yang terjadi lebih besar dibandingkan dengan saat kondisi muka air tanah pada galian atau tanpa adanya air.

\section{DAFTAR PUSTAKA}

Badan Standardisasi Nasional. (2017). “SNI Geoteknik 8460:2017 - Persyaratan Perancangan Geoteknik”. Badan Standardisasi Nasional, Jakarta.

FHWA. (1999). “Geotechnical Engineering Circular No.4 Ground Anchor and Anchorage Systems”. US Department of Transportation, Washington D.C.

Hardiyatmo, H.C. (2010). “Analisis dan Perancangan FONDASI bagian II”. Gadjah Mada University Press, Yogyakarta.

Xanthakos, P.P. (1991). “Ground Anchors and Anchored Structures”. John Wiley \& Sons, New York. 